\title{
ТЕОРИЯ КОММУНИКАЦИИ КАК КОГЕРЕНТНАЯ ОБЛАСТЬ В КОНТЕКСТЕ УПРАВЛЕНЧЕСКОГО ВОЗДЕЙСТВИЯ НА РУБЕЖЕ ХХ-ХХІ ВВ.
}

\author{
Андриянова Татьяна Владимировна, \\ andriyanova.tv@gmail.com \\ Курский государственный университет, \\ Россия, 305004, г. Курск, ул. Радищева, 29
}

\begin{abstract}
Андриянова Татьяна Владимировна, кандидат социологических наук, доцент кафедры социологии Курского государственного университета.

Актуальность определяется необходимостью обозначить контекст управленческого воздействия в зарубежных исследованиях теории коммуникации в конце XX - начале XXI вв. с перспективой конструирования социальных процессов современного общества. Объектом исследования выступает теория коммуникации как когерентная исследовательская область. Предмет - определение контекста управленческого воздействия в разработках теории коммуникации обозначенного периода. Цель работы - выявление истоков междисциплинарного дискурса теории коммуникации, теоретической матрищы формирования ее когерентной области и определение контекста управленческого воздействия в построении коммуникативных процессов современного общества. Методология основывается на междисциплинарном подходе, сформулированном в работах по теории коммуникации Р. Крэйга, С. Литтлджона, Дж. Делии, Ф. Дэнса; языковой теории Т. Тейлора. Выводы: контекст управленческого воздействия в рамках когерентной области теории коммуникации представляется наиболее востребованным в рамках социокультурной традиции, осмысляемой как процесс производства и воспроизводства социального порядка.
\end{abstract}

Ключевые слова: Теория коммуникации, когерентная область, управленческое воздействие, теоретическая матрица, модели коммуникации.

\section{Степень научной разработанности темы исследования}

Осмысление идей зарубежной коммуникационной теории в работах отечественных авторов позволяет затронуть перспективные в исследовательском отношении вопросы формирования контекста управленческого воздействия на общество, его теорию и практику. Отмечая, что основной массив таких работ связан с периодом конца XX начала XXI вв., выделим наиболее интересные ракурсы рассмотрения метадискурсивной коммуникационной теории Р. Крэйга и его современников в русле избранного подхода. На определенный резонанс, вызванный текстами работ американских исследователей коммуникации, указывает в своей статье Н.В. Казаринова и обсуждает это как повод вновь обратиться, например, к теоретической матрице Крэйга в учебнометодическом и научном дискурсе. Автор подчеркивает недооцененность в отечественном знании той научной дискуссии, которая развернулась в международном научном сообществе после обнародования им концепции теории коммуникации как исследовательской области. Между тем само ее представление Крэйгом в эссе «Теория коммуникации как область» 1999 г. уже имеет оригинальный научный дизайн и стиль «сценированного диалога» теоретического и практического метадискурсов [1, с. 178]. Казаринова останавливается на учебно-методическом ракурсе рассмотрения идей тео- 
рии коммуникации в двух аспектах: опредмечивание этой области в учебниках и учебных пособиях с попыткой классифицировать разные исследовательские подходы и использование теории коммуникации Крэйга как основы для учебных заданий. И тот и другой аспекты страдают, по ее мнению, от избыточного теоретизирования и практики простого воспроизводства смысла и не выходят за это пространство. Здесь необходимо отметить, что потенциал управленческого воздействия теории коммуникации также не всегда отражается в методических материалах. Сходным образом Казаринова представляет и картину научного осмысления теории коммуникации в отечественных работах [1, с. 179]. В качестве парадоксов теории Крэйга она выводит следующие: профессиональное сообщество, следуя принципам диалогически-диалектической модели, не всегда способно воплотить ее принципы полностью; в ходе взаимодействия групп профессионалов и непрофессионалов выявляется недоверие к первым в практике повседневного применения коммуникации; репрезентация темы доверия в процессе коммуникации требует такой верификации, которая может его в конечном итоге подорвать [1, c. 182].

В то же время И.П. Кужелева-Саган, проанализировав в своей работе более 10 подходов отечественных авторов к зарубежным концепциям коммуникации, отмечает в них два основных потока по принадлежности к социально-философскому и социально-научному знанию, отмечая, что такое деление является условным, т. к. все они имеют общую философскую природу [2, с. 114]. По степени общности, на взгляд автоpa, все концепции можно представить шкалой от более общих к частным, но она является не жестко закрепленной, т. к. одна и та же парадигма может рассматриваться на обоих ее полюсах. Примером является социокультурная парадигма, представленная в трудах М. Гундарина, как «глобальная», а у И. Архангельской, опирающейся на работы Крэйга, она является одним из семи подходов к коммуникации [2, с. 115]. Останавливается Кужелева-Саган и на кросс-культурном дискурсе теории коммуникации, отмечая, что отечественная наука долгое время не имела возможности «встроиться» в зарубежный исследовательский контент по объективным причинам и, несмотря на это, выдвинула целый ряд перспективных ученых в этом направлении (В. Вернадский, М. Бахтин, Л. Выготский). Однако и американские исследователи, в том числе Ф. Дэнс, выражали сожаление по поводу отсутствия у них возможности познакомиться с работами русских авторов (особенно лингвистического направления и психологического подхода). Этот вывод подтверждают исследования, проведенные в конце XX в. Дж. Андерсоном, который, проанализировав содержание семи учебников по теории коммуникации, выделил 249 различных теорий, 195 из которых появлялись только в одной из семи книг [3]. Проблема здесь заключается в многообразии теории коммуникации и ее определений в зарубежной и отечественной науке, которую многие ученые предлагают решить за счет формулирования единой теории, в то время как американские авторы, в частности Крэйг, наоборот считают это непрагматическим подходом и предлагают сформулировать общую когерентную исследовательскую область для теории и практики коммуникации.

Причем на рубеже XX-XXI вв. в Америке уже происходило переосмысление накопленных знаний в теории коммуникации, в частности к этой теме обращался Крэйг, утверждая, что существуют определенные трудности для точной идентификации данной области исследования [4]. При этом он отмечал, что некоторые ее критерии уже достаточно четко определены как в его собственных трудах, так и в работах Андерсона в 1980-90-е гг. [5]. Кроме этого, существовал целый ряд исследований по истории теории коммуникации и коллективные работы (справочники, энциклопедии, антологии, 
базы данных), в которых можно было найти различные достаточно открытые и полезные подходы. Вместе с тем исследователи отмечали, что разные авторы, по-видимому, работали в основном в отдельных областях теории коммуникации, вследствие чего общая область дискуссий выстраивалась достаточно сложно. В этот период в книгах и статьях по теории коммуникации редко упоминались другие работы, за исключением узких (междисциплинарных) специальностей и исследовательских школ.

Далее, в упоминавшейся нами статье, Кужелева-Саган обращает внимание на более важный с ее точки зрения момент, касающийся бинарных оппозиций, выделенных в концепциях коммуникации разных авторов, которые она в итоге выразила в двух принципиальных позициях и представила в соответствующей таблице, которую далее охарактеризовала как матрицу [2]. Здесь, безусловно, тоже не обошлось без влияния метадискурсивной теории Крэйга, имеющего свою собственную позицию относительно принципа бинарности и теоретическую матрицу в двух таблицах [4]. Относительно бинарного выбора Крэйг предостерегал использовать его в качестве принципа определения коммуникации, показывая это на примере двух моделей (трасмиссионной и конститутивной) коммуникации. В частности, он указывал, что коммуникация - это не бинарный выбор между этими двумя моделями, потому что трансмиссионная модель в данном случае воспринимается не больше, чем упрощенная схема, а значит такое определение неточно [4, p. 127].

Интересующий нас контекст управленческого воздействия в русле теории коммуникации можно выделить в статье Н.П. Пименова, посвященной вопросам политической коммуникации. Он отмечает, что социальный подход к коммуникации позволяет рассматривать ее как «контактный вид социальной связи, устанавливаемый на основе направленной передачи информации» [6, с. 296] и разделяет здесь процесс коммуницирования как попытку установить связь между акторами и сам акт коммуникации, т. е. свершившийся контакт. Ссылаясь на точку зрения Т.М. Дридзе, Пименов отмечает субъектные отношения в коммуникации с двунаправленной обратной связью, построенной как диалог в отличие от однонаправленного информационного процесса [6]. Классификация теоретических моделей в данном исследовании основывается на бинарном выборе «линейность-нелинейность» с обязательным взаимодействием коммуникатора и коммуниканта и отличается количеством входящих в нее элементов и зависимостью от внешней среды. Теория Крэйга в части теоретической матрицы отнесена ко второму типу, и в ней выделена социокультурная традиция как ведущая в объяснении закономерностей процесса коммуникации в управленческом (в данном случае политическом) воздействии [6, с. 297].

В исследованиях О.И. Матьяш - основателя и первого президента Российской коммуникативной ассоциации - особый акцент делается на понимании коммуникации как универсальной социокультурной практики [7], но в то же время признается, что сам процесс коммуникации пока не имеет универсальной модели описания в поле научного знания и учебных дисциплин. Рассматривая институционализацию коммуникации как исследовательской дисциплины в США, Матьяш указывает на наличие в ней крупного головного центра - Национальной коммуникативной ассоциации, около 50 ее подразделений, занимающихся разными ее вопросами и более 1000 университетских программ в этом направлении [7]. Среди всего многообразия выделим образовательную программу Communication and Leadership (Коммуникация и руководство (лидерство)), в рамках которой изучаются вопросы управленческого воздействия на общество, определяющие в свою очередь функциональные, структурные и понятийные особенности данной отрасли. 
Подводя предварительные итоги обзора уже имеющихся отечественных исследований в рамках теории коммуникаций, отметим, что мы не обнаружили здесь разработанные подходы к интересующему нас вопросу формирования управленческого воздействия на общества. Его имеющиеся истоки мы показали выше и теперь обратимся к непосредственному анализу данного феномена с точки зрения авторского подхода.

\section{Концептуальная модель исследования}

В своих работах Крэйг указывал, что коммуникация как дисциплина изначально пыталась позиционировать себя как своего рода междисциплинарный центр обмена информацией для всех этих дисциплинарных подходов [4]. С одной стороны, это привело к тому, что дух междисциплинарности присутствовал в исследованиях и культивировался как одно из наиболее достойных качеств теории коммуникации, с другой объединение нескольких различных дисциплинарных подходов затрудняло ее представление как целостной области.

Американский исследователь Ф. Дэнс опубликовал на рубеже 1950-60-х гг. ряд статей, в которых рассмотрел 95 определений коммуникации и пришел к выводу, что:

- эти определения отличаются во многих отношениях (выделил 15 смысловых составляющих отличий);

- понятие «коммуникация» лучше теоретически представить как «семью» связанных понятий, а не унитарную концепцию, чтобы избежать возможных теоретических разногласий [8].

В 1972 г. Р. Баддом и Б. Рубеном была составлена антология теории коммуникации, главы которой представляли 24 дисциплинарных подхода к ней, расположенных в алфавитном порядке: от антропологии к зоологии [9]. А в 1980-е гг. С. Литтлджон наряду с Дж. Делией подчеркивал междисциплинарное происхождение этой области, схематически проследив вклад в теорию коммуникации таких разнообразных дисциплин, как литература, математика, инженерия, социология, психология и т. д. [10, 11$]$.

Работая в позитивистской традиции, которая позволяла стабильно поддерживать концепцию теории коммуникации, Дэнс, возможно, недооценивал трудность интеграции определений, эклектически выведенных из дисциплин с несоизмеримыми интеллектуальными целями, часто включающих радикально различные ее обоснования. Учитывая обилие определений коммуникации и трудность их интеграции или принятия какого-либо удовлетворительного решения, Б.О. Фишером и М.Э. Мерфи в конце XX в. было установлено, что спорить об определениях коммуникации бессмысленно.

Одним из самых интересных фактов в теории коммуникации, на который обращали внимание ученые, являлся тот, что она возникла более или менее независимо во многих академических дисциплинах. Согласно Дж. Питерсу исследования коммуникации были интеллектуально «обеднены» отчасти из-за особого способа, которым эта дисциплина была институционализирована в университетах США. Он указывал, что термин «коммуникация» был использован У. Шраммом и другими в качестве институционального легитимирующего устройства таким образом, что исключал какое-либо связное определение области, ее интеллектуального фокуса и миссии [12]. Теория коммуникации к этому времени была широко изучена и теоретически проработана, но попытки претендовать на всю академическую область теории и исследований коммуникации все же существовали: «коммуникационные исследования стали интеллектуальным Тайванем, претендующим на то, чтобы быть всем Китаем, когда на самом деле он был изолированным маленьким островом» [12, p. 545]. 
Крэйг описывал и самый, на его взгляд, вопиющий случай, связанный с послевоенным периодом и появлением математической теории информации К. Шеннона и У. Уивера, которую эти исследователи рекламировали в русле теории коммуникации как доказательство потенциального научного статуса своей области, хотя они не имели никакого отношения к ее созданию, не очень понимали и редко находили ей реальное применение в своих исследованиях [4].

На первый план в эти годы вышла и так называемая проблема «бесплодной эклектики» («sterile eclecticism») [4, p. 123], означающая, по Крэйгу, непродуктивное сочетание разных традиций в русле теории коммуникации. Она осознавалась ведущими учеными в области коммуникации, и с их стороны было стремление преодолеть ее путем разработки систематических, теоретически обоснованных исследовательских программ. Но поскольку большинство их теорий и исследовательских парадигм были заимствованы из других дисциплин, это означало, по сути, инициирование исследовательских программ в области коммуникации, основанных на исследовательских программах в этих дисциплинах, так что многие исследования в области политической коммуникации, например, оказались немногим больше, чем политическая наука как практика в области коммуникации [12]. Точно так же многие исследования межличностной коммуникации в данном контексте можно считать отчасти экспериментальной социальной психологией, применяемой в области коммуникации. По мнению Крэйга, междисциплинарность и кросс-дисциплинарное заимствование сами по себе являются полезными практиками и их следует поощрять, чтобы смягчить фрагментацию знаний между дисциплинами, а по мнению Питерса, проблема здесь заключалась в том, что в основном эти заимствования использовались для поддержания институциональных претензий на дисциплинарный статус без формулирования какой-либо последовательной, отличительной направленности или миссии этой предполагаемой коммуникационной дисциплины.

Крэйг противопоставлял идее «бесплодной эклектики» идею «продуктивной фрагментации» (productive fragmentation), дающей возможность наиболее продуктивно исследовать коммуникацию, обогащая свою собственную область и делая ее в итоге когерентной. Пока же каждый фрагмент исследования коммуникации был продуктивен в своей собственной области, и это способствовало появлению все большего количества теорий коммуникации, но не определяло область теории коммуникации [4].

\section{Теория коммуникации как когерентная исследовательская область: теоретическая матрица Крэйга и контекст управленческого воздействия}

Формулируя на первом этапе цель представления области как установление диалогико-диалектической согласованности, Крэйг предлагал не ориентироваться на единую придуманную теорию коммуникации, находящуюся за горизонтом, так как такая теория всегда будет недосягаема, и исследователи, вероятно, не хотели бы ее иметь, даже если бы она была достижима [4, p. 123]. В качестве аргументов он приводил следующие утверждения. Во-первых, ни одна активная область исследования не основывается на единой теории. Во-вторых, совершенно «связная» область была бы статичной, «мертвой». В-третьих, сама практика коммуникации очень динамична и быстро развивается в повседневной обстановке непредвиденных обстоятельств и конфликтов. Таким образом, теории коммуникации, по мнению Крэйга, в перспективе не могли достигнуть окончательной, единой формы [4, p. 124], поэтому в он предлагал качестве цели выбрать условия свободного академического дискурса между разными научными школами. 
Известный постулат Крэйга и других авторов этого времени о диалогическидиалектической согласованности связан с формированием когерентной области и включает в себя принципы:

- поиска путей осмысления определенных противоречий и возможных взаимодополнений в различных типах теории коммуникации;

- определение перспективы полноценного развития и взаимообогащения этих теорий;

- определения общего поля для дискуссий.

И в качестве основного метода формирования когерентной области на страницах своих работ Крэйг предлагал определенную теоретическую матрицу, построенную на основе двух принципов, представленных ниже:

1. Первый был связан с конститутивной моделью коммуникации, сформировавшейся в ходе концептуализации области теории коммуникации. Говоря о конститутивности, Крэйг отмечал, что на фоне общего расцвета теории коммуникации с конца 1980-х гг., она отражала нарастающее среди некоторых ученых убеждение в когерентности данной области исследования как центральной для социальной мысли: концептуализируя коммуникацию, мы конструируем “коммуникативную” перспективу социальной реальности и таким образом определяем сферу и цель коммуникативной дисциплины, отличной от других социальных дисциплин [4].

Продолжая обсуждение формирования когерентной исследовательской области, остановимся на взглядах профессора Колорадского университета С. Дитца, который указывал, что новые дисциплины возникают тогда, когда существующие способы объяснения не дают ответов на центральный набор новых социальных проблем [14]. Он придерживался формировавшейся в то время «коммуникативной перспективы», которая фокусировалась на описании того, как внутренний мир, внешний мир, социальные отношения и средства выражения взаимно конституируются с процессом взаимодействия как его собственным лучшим объяснением [14]. С аргументами Дитца, выдвинутыми в поддержку конститутивной модели коммуникации были согласны многие, т. к. они не являлись чисто теоретическими, а позволяли реагировать, в том числе с помощью управленческих ресурсов, на изменяющуюся социальную ситуацию и следующие проблемы современности:

- определение того, кто и каким образом участвует в социальных процессах, конструирующих личность, социальный порядок и коды коммуникации;

- увеличение потребности широкого демократического участия в конструировании социальной реальности;

- увеличение культурного разнообразия и взаимозависимости, что приводило к эрозии культурных основ традиционных идей и институтов и т. д.

И если конститутивная модель могла способствовать достижению целей свободы, демократии и терпимости, то трансмиссионная могла использоваться для укрепления авторитета экспертов [4].

Суть здесь сводилась к определенной «академической конкуренции» между конститутивной и трансмиссионной моделями. Эту конкуренцию исследователи пытались вывести в определенное прагматическое русло. Согласно трансмиссионной модели, коммуникация есть процесс отправки и получения сообщений или передачи информации от одного сознания к другому [4]. Такая трактовка доминировала в повседневной и в академической мысли, пока Питерс и Тайлор не сделали вывод о ее эмпирических и солипсистских корнях, что привело к ее трактовке как идеологически устаревшей и требующей переосмысления, а также дополнения моделью, которая концептуализирует 
коммуникацию как конститутивный процесс, который производит и воспроизводит общий смысл коммуникации.

К особенностям ее управленческого воздействия можно отнести способность представить разные модели коммуникации как различные способы символического конституирования коммуникативного процесса для конкретных целей. Однако коммуникация может быть символически конституирована многими различными способами, в том числе и посредством трансмиссии, что находит свое отражение в рамках кибернетической традиции теории коммуникации Г. Бейтсона, К. Криппендорфа и Н. Лумана [15-17], где она рассматривается как одно из проявлений парадоксальной рефлексивности между смыслом и контекстом или сообщением и метасообщением.

Несмотря на эти парадоксы, представления о коммуникации в рамках трансмиссионной модели, какими бы философскими недостатками они ни отличались, имели культурную ценность: например, в евро-американских культурах коммуникация традиционно рассматривалась как процесс передачи. Поэтому трансмиссионная модель использовалась достаточно часто: полезно прагматически различать источники и приемники коммуникации, отображать поток информации через системы или думать о сообщениях как о “контейнерах смысла" или о коммуникации как о преднамеренном акте, совершаемом для достижения некоторого ожидаемого результата [4, p. 127]. Модели трансмиссии полезны и в том смысле, что они культивировали осмотрительный подход к разнообразию и относительности перспектив и постоянно присутствующим опасностям искажения и непонимания в коммуникации. Среди сторонников конститутивной модели исключение составлял Питерс, который обращал внимание на достоинства трансмиссионной модели.

Кроме этого, конститутивная модель коммуникации могла принимать саму коммуникацию за феномен, теоретически обоснованный в рамках строго определенных традиций, без учета других, чем ограничивала когерентность области теории коммуникации. Так, Крэйг предостерегал от синонимичного использования конститутивной метамодели с социокультурной моделью коммуникации первого порядка [4, p. 128]. Таким образом, существовало множество различных способов, с помощью которых коммуникация осмыслялась или символически конституировалась в рамках конститутивной метамодели, что способствовало формированию ее когерентной области как метадискурса в контексте практической дисциплины.

При изучении этих источников можно обнаружить несколько важных тем в интересующем нас контексте управленческого воздействия:

- коммуникация как академическая дисциплина охватывает коммуникативную перспективу социальной реальности, которая радикально отличается от других дисциплинарных перспектив, в связи с чем она опровергает их объяснительные схемы и выступает не как вторичный феномен, детерминированный предшествующими упомянутыми в этих дисциплинах факторами, а является первичным, конститутивным социальным процессом, который объясняет все эти другие факторы [4];

- рефлексивность отношений между теорией коммуникации и культурой помогает воссоздавать и объяснять различные социальные явления, опираясь на обыденные, культурно обоснованные способы мышления о коммуникации, что, в свою очередь, дает эффект обратного влияния и изменения повседневного мышления и практик;

- предыдущие выводы позволяют обозначить практические, в том числе и политические, последствия теории коммуникации, что явно указывает на их властный управленческий потенциал, т. к. они влияют на общество, служат интересам более привилегированных и влиятельных его слоев: «например, трансмиссионная модель комму- 
никации может служить интересам технических экспертов, таких как ученые и инженеры, когда она используется для укрепления культурных убеждений, подчеркивающих ценность экспертов как надежных источников информации» [4];

- установление того факта, что представления о коммуникации развивались исторически и лучше всего понимаются в более широком контексте культурной и интеллектуальной истории, дает основание выделить в них управленческий аспект.

2. Второй принцип диалогико-диалектической матрицы Крэйга формулировался на основе идей книги британского исследователя Т. Тейлора «Взаимное непонимание: скептицизм и осмысление языка и интерпретации» (1992) как еще одно обоснование теории коммуникации как когерентной области. Идеи Тейлора кратко можно представить в интересующем нас контексте управленческого воздействия следующим образом [18]:

- представление технической практики осмысления языка, интерпретации, коммуникации и понимания как производной от обычной, повседневной практики обсуждения того, что люди говорят и делают;

- общая вера в то, что люди обычно понимают высказывания друг друга и выход исследователя на установление правдоподобности предполагаемой достоверности некоторых из общих метадискурсивных мест на основе риторической апелляции к ним каждой языковой теории и скептическому анализу других;

- понимание теории языка как интеллектуального метадискурса, структурированного в рамках замкнутой «самореферентной игры», единственным выходом из которой является отказ от объяснения того, как возможна коммуникация и обращение вместо этого к тому, как рефлексивно коммуникация осуществляется на практике.

Обобщая отмеченные идеи Тейлора и их осмысление в работах Крэйга, выделим здесь определенный управленческий контекст. Во-первых, это предположение, что исследовательская практика теории коммуникации в значительной степени вытекает из нашей обычной, повседневной практики коммуникации [4]. Во-вторых, представление теории коммуникации как когерентной области открывает перспективу широкого научного обсуждения проблем коммуникации как социальной практики и теоретического метадискурса, который возникая из практического метадискурса, расширял и обогащал его [4].

В значительной части работ Крэйга этого периода признавался потенциал теории коммуникации для развития данного феномена как социальной практики и как практической дисциплины. Суть его можно представить следующим образом: коммуникация может быть осмыслена с самых разных точек зрения, поэтому область теории коммуникации становится областью для обсуждения относительных достоинств альтернативных практических теорий.

Эта дискуссия об альтернативных теориях составляла то, что Крэйг называл теоретическим метадискурсом, т. к. коммуникация имеет потенциал для того, чтобы стать практической дисциплиной, прежде всего потому, что понятие «коммуникация» является весьма значимым в жизненном мире. Еще в середине прошлого века американский исследователь Р. Маккеон пришел к выводу, что в русле существующей культуры мы склонны думать, что все проблемы по сути являются проблемами общения [19]. И именно там, как отмечали Т. Катриель и Дж. Филипсен, мы часто обнаруживаем, что нам проще «сесть и поговорить» для того, чтобы решить проблемы в отношениях [20]. Такое «ритуальное» закрепление общения как единственных уз, которые могут объединять разнообразные сообщества, дает возможность преодолевать обширные пространственные и культурные разрывы, которые разделяют людей. Коммуникация здесь представлялась как тема, широко обсуждаемая во всех слоях общества с учетом того, 
насколько она важна и заслуживает изучения, чтобы улучшать ее. Крэйг и Трейси отмечали, что теория коммуникации может быть построена индуктивно через критическое осмысление повседневной практики, частично путем транскрибирования и теоретической реконструкции «размещенных идеалов» («situated ideals»), артикулируемых самими людьми в их повседневном метадискурсе. Этот критико-индуктивный способ построения теории коммуникации был исследован ими в более ранних работах по «обоснованной практической теории» [21].

В целом исследования Крэйга и других авторов теории коммуникации на рубеже XX-XXI вв. позволяют сделать некоторые обобщения.

Коммуникация имеет потенциал для того, чтобы быть практической дисциплиной отчасти потому, что само это понятие является важной теоретической категорией в широком спектре исследовательских дисциплин, из которых можно извлечь богатый набор концептуальных ресурсов для исследования практики коммуникации. В этих уже сложившихся традициях теории коммуникации предлагаются различные альтернативные словари, которые могут быть представлены как альтернативные способы концептуализации проблем практики коммуникации. Интеллектуальное наследие теории коммуникации представляет собой вторую отправную точку для построения области теории коммуникации. Этот критико-дедуктивный способ построения теории коммуникации предлагал Крэйг: теория коммуникации может быть построена как дедуктивно, отталкиваясь от теории, так и индуктивно, отталкиваясь от практики [4].

Несмотря на то, что теоретические идеи о коммуникации были разработаны в различных дисциплинах с несоизмеримыми интеллектуальными целями, тем не менее исследователи коммуникации предполагали, что каждая из этих идей потенциально актуальна для практики: одна интересная, хотя, по общему признанию, и «спекулятивная» причина здесь заключается в том, что коммуникация, возможно, была теоретически разработана в различных дисциплинах в течение XX в. потому, что она стала культурно важной категорией социальной практики» [4]. Это предположение согласуется с рефлексивностью или взаимным влиянием теории коммуникации и культурной практики Кэри, Дитца и других авторов. С риторической точки зрения один из способов легитимации академической дисциплины в культуре состоит в том, чтобы установить ее социальную значимость, показав, что она может сказать что-то важное о таких культурно значимых темах и практических проблемах, как коммуникация в современном обществе.

Если широкое теоретическое осмысление коммуникации во многих академических дисциплинах возникло отчасти из стремления обозначить ее практическую значимость, то междисциплинарное наследие теории коммуникации в какой-то степени предназначено для формулирования целей практической дисциплины. По Крэйгу, метод реконструкции традиций теории коммуникации необходим, чтобы подчеркнуть их практическую значимость, что в общих чертах наследует Тейлору. Предполагалось, что теоретический метадискурс (т. е. теория коммуникации) выводит и теоретически осмысляет практический метадискурс (повседневные способы размышления о коммуникации) и при этом оба, с одной стороны, риторически апеллируют к определенным общим метадискурсивным местам, что делает теорию правдоподобной с точки зрения непрофессионала, а с другой - критически обсуждают другие общие метадискурсивные места.

\section{Выводы}

Значимость основных идей в рамках когерентной области теории коммуникации, сформулированных зарубежными авторами в конце XX - начале XXI вв., приобретает особую актуальность в современных процессах управленческого воздействия на соци- 
ум, что находит свое отражение в ряде работ ведущего отечественного специалиста в данной области Ф.И. Шаркова [22] и других ученых, а также авторских публикаций [23-26]. Хотелось бы отметить особую значимость здесь социокультурной традиции теории коммуникации, понимаемой в русле процесса производства и воспроизводства общественного порядка, и отметить следующее:

- теория коммуникации как научная дисциплина способна охватывать коммуникативную перспективу социальной реальности, а сама коммуникация выступает здесь первичным конститутивным социальным процессом;

- различные теории коммуникации, с одной стороны, оказывают значительное влияние на повседневные социальные практики мышления и действия, трансформируя их, с другой - испытывают обратное рефлексивное воздействие;

- основные модели коммуникации, представляющие собой определенный ответ на актуальные проблемы современного общества (эрозия социокультурных основ традиционных идей и институтов, требование демократического участия в процессах конструирования социальной реальности), могут быть использованы для укрепления авторитета управляющих органов и символического конструирования коммуникативного процесса с определенными целями;

- «ритуальное закрепление» (Т. Катриель, Дж. Филипсен) общения как неких уникальных связей, объединяющих культурные «разрывы», является важной коммуникативной функцией социального управления;

- управленческое воздействие в данном контексте рассматривается как возможность влияния на общественные структуры социальных групп с целью укрепления определенных социокультурных убеждений посредством экспертных мнений;

- управленческий резерв теории коммуникации заключается в способности регулировать вопросы общественного участия в социальных процессах, конструирующих социальный порядок, личность и коды коммуникации.

\section{СПИСОК ЛИТЕРАТУРЫ}

1. Казаринова Н.В. Парадоксы дисциплинарной матрицы Роберта Крейга // Вестник СанктПетербургского университета. Социология. - 2019. - Т. 12. - Вып. 2. - С. 176-187.

2. Кужелева-Саган И.П. Основные исследовательские парадигмы в сфере теории коммуникации: социально-философский аспект // Вестник ТГПУ. Серия «Гуманитарные науки». - 2006. - Вып. 7 (58). C. $106-116$.

3. Anderson J.A. Communication theory: epistemological foundations. - New York: Guilford Press, 1996. 259 p.

4. Craig R.T. Communication theory as a field // Communication Theory. - 1999. - № 9. - P. $119-161$.

5. Craig R.T. Communication as a practical discipline // Rethinking communication. V. 1. Paradigm issues / Eds. B. Dervin, L. Grossberg, B.J. O’Keefe, E. Wartella. - Newbury Park, CA: Sage, 1989. - P. 97-122.

6. Пименов Н.П. Сравнительный анализ теоретико-методологических подходов к изучению современных политических коммуникаций // Известия Алтайского государственного университета. - 2014. T. 2. - № 4 (84). - C. 295-299.

7. Матьяш О.И. Плюрализм в современной науке о коммуникации: диалог подходов и традиций // Коммуникология. - 2014. - Т. 5. - № 3. - С. 63-78.

8. Dance F.E.X. The «concept» of communication // Journal of Communication -1970. - № 20 - P. $201-210$.

9. Approaches to human communication / Eds. Budd R.W., Ruben B.D. - Rochelle Park, NJ: Hayden, 1972. $464 \mathrm{p}$.

10. Littlejohn S.W. An overview of contributions to human communication theory from other disciplines // Human communication theory: Comparative essays / Ed. by F.E.X. Dance. - New York: Harper \& Row, 1982. - P. 243-285.

11. Delia J.G. Communication research: a history / Handbook of Communication Science / Eds. C.R. Berger and S.H. Chaffee. - Newbury Park, CA: Sage, 1987. - P. 20-98. 
12. Peters J.D. Institutional sources of intellectual poverty in communication research // Communication Research. - 1986. - № 13. - P. 527-559.

13. Shotter J. Textual violence in academe: on writing with respect for one's others // Transgressing discourses: communication and the voice of other / Eds. M. Huspek, G.P. Radford. - Albany, NY: SUNY Press, 1997. P. 17-46.

14. Deetz S.A. Future of the discipline: the challenges, the research, and the social contribution // Communication Yearbook, 17 / Ed. by S.A. Deetz. - Thousand Oaks, CA: Sage, 1994. - P. 565-600.

15. Bateson G. Steps to an ecology of mind. - New York: Ballantine Books, 1972. - 517 p.

16. Krippendorff K. Seeing oneself through others' eyes in social inquiry // Transgressing discourses: communication and the voice of other / Eds. M. Huspek, G.P. Radford. - Albany, NY SUNY Press, 1997. - P. 4772.

17. Luhmann N. What is communication? // Communication Theory. - 1992. - № 2. - P. 251-259.

18. Taylor T.J. Mutual misunderstanding: scepticism and the theorizing of language and interpretation. Durham, NC: Duke University Press, 1992. - 320 p.

19. McKeon R. Communication, truth, and society // Ethics. - 1957. - № 67. - P. 89-99.

20. Katriel T., Philipsen, G. «What we need is communication»: «Communication» as a cultural category in some American speech // Communication Monographs. - 1981. - № 48. - P. 301-317.

21. Craig R.T., Tracy K. Grounded practical theory: the case of intellectual discussion // Communication Theory. -1995 . - № 5. - P. 248-272.

22. Шарков Ф.И. Социальные сети как основа формирования пространства публичных коммуникаций // Коммуникология. - 2019. - Т. 7. - № 4. - С. 32-40.

23. Андриянова Т.В. Коммуникационная теория Р. Крэйга: дискурсивные практики и тенденции взаимодействия в управлении субъектом // Коммуникология. - 2019. - Т. 7. - № 2. - С. 15-24.

24. Андриянова Т.В. Региональная культура: субъектно-объектные взаимодействия в сфере управления (на примере Курской области) // Векторы благополучия: экономика и социум. - 2019. - № 4 (35). C. $17-30$.

25. Andriyanova T.V., Kirnosova E.N., Starodubtseva I.F. Government order and its significance in the work of the regional cultural establishments // Far East Con: Proc. of the International Scientific Conference (ISCFEC 2018). Part of series: AEBMR. - V. 47. - P. 175-190. URL: https://doi.org/10.2991/iscfec18.2019.44 (дата обращения: 28.01.2021).

26. Андриянова Т.В. Демографический фактор управленческих решений как основа социокультурного развития региона // Социальная динамика населения и устойчивое развитие: II Всероссийская научно-практическая конференция с международным участием: сборник тезисов / под общ. ред. А.И. Антонова. - М.: МАКС Пресс, 2019. - С. 18-21.

Поступила 02.02.2021 г. 


\title{
COMMUNICATION THEORY AS A COHERENT FIELD IN THE CONTEXT OF MANAGERIAL INFLUENCE AT THE TURN OF THE XX-XXI CENTURIES
}

\author{
Tatiana V. Andriyanova, \\ andriyanova.tv@gmail.com \\ Kursk State University, \\ 29, Radishchev street, Kursk, 305004, Russia.
}

Tatiana V. Andriyanova, Cand. Sc., associate professor, Kursk State University.

The relevance of the study is determined by the need to identify the context of managerial influence in foreign studies of the communication theory in the late XX - early XXI centuries with the prospect of constructing social processes in modern society. The object is the communication theory as a coherent research area. The subject of the study is to determine the context of managerial influence in the development of the communication theory of the designated period. The purpose of the study was to identify the origins of the interdisciplinary discourse of the communication theory, the theoretical matrix of the formation of its coherent domain, and to determine the context of managerial influence in the construction of the communicative processes of modern society. The methodology was based on an interdisciplinary approach formulated in the works on the communication theory by R. Craig, S. Littlejohn, J. Delia, F. Dance; the language theory of T. Taylor. Conclusions. The context of managerial influence within the coherent field of communication theory seems to be most in demand within the socio-cultural tradition, interpreted as a process of production and reproduction of the social order.

Key words: Communication theory, coherent field, management impact, theoretical matrix, communication models.

\section{REFERENCES}

1. Kazarinova N.V. Paradoksy distsiplinarnoy matritsy Roberta Kreyga [Robert Craig's disciplinary matrix paradoxes]. Vestnik Sankt-Peterburgskogo universiteta. Sotsiologiya, 2019, vol. 12, Iss. 2, pp. 176-187.

2. Kuzheleva-Sagan I.P. Osnovnye issledovatelskie paradigmy v sfere teorii kommunikatsii: sotsialnofilosofskiy aspekt [Basic research paradigms in the field of communication theory: socio-philosophical aspect]. Vestnik TGPU. Seriya «Gumanitarnye nauki», 2006, Iss. 7 (58), pp. 106-116.

3. Anderson J.A. Communication theory: epistemological foundations. New York, Guilford Press, 1996. 259 p.

4. Craig R.T. Communication theory as a field. Communication Theory, 1999, no. 9, pp. 119-161.

5. Craig R.T. Communication as a practical discipline. Rethinking communication. Vol. 1. Paradigm issues. Eds. B. Dervin, L. Grossberg, B.J. O’Keefe, E. Wartella. Newbury Park, CA, Sage, 1989. pp. 97-122.

6. Pimenov N.P. Sravnitelny analiz teoretiko-metodologicheskikh podkhodov k izucheniyu sovremennykh politicheskikh kommunikatsiy [Comparative analysis of theoretical and methodological approaches to the study of modern political communications]. Izvestiya Altayskogo gosudarstvennogo universiteta, 2014, vol. 2 , no. 4 (84), pp. 295-299.

7. Matyash O.I. Plyuralizm v sovremennoy nauke o kommunikatsii: dialog podkhodov i traditsiy [Pluralism in the modern science of communication: a dialogue of approaches and traditions]. Kommunikologiya, 2014, vol. 5, no. 3, pp. 63-78.

8. Dance F.E.X. The «concept» of communication. Journal of Communication, 1970, no. 20, pp. 201-210.

9. Approaches to human communication. Eds. Budd R.W., Ruben B.D. Rochelle Park, NJ, Hayden, 1972. $464 \mathrm{p}$.

10. Littlejohn S.W. An overview of contributions to human communication theory from other disciplines. $\mathrm{Hu}$ man communication theory: Comparative essays Ed. by F.E.X. Dance. New York, Harper \& Row, 1982. pp. 243-285. 
11. Delia J.G. Communication research: a history. Handbook of Communication Science. Eds. C.R. Berger, S.H. Chaffee. Newbury Park, CA, Sage, 1987. pp. 20-98.

12. Peters J.D. Institutional sources of intellectual poverty in communication research. Communication Research, 1986, no. 13, pp. 527-559.

13. Shotter J. Textual violence in academe: on writing with respect for one's others. Transgressing discourses: communication and the voice of other. Eds. M. Huspek, G.P. Radford. Albany, NY, SUNY Press, 1997. pp. 17-46.

14. Deetz S.A. Future of the discipline: the challenges, the research, and the social contribution. Communication Yearbook, 17. Ed. by S.A. Deetz. Thousand Oaks, CA, Sage, 1994. pp. 565-600.

15. Bateson G. Steps to an ecology of mind. New York, Ballantine Books, 1972. 517 p.

16. Krippendorff K. Seeing oneself through others' eyes in social inquiry. Transgressing discourses: communication and the voice of other. Eds. M. Huspek, G.P. Radford. Albany, NY SUNY Press, 1997. pp. 47-72.

17. Luhmann N. What is communication? Communication Theory, 1992, no. 2, pp. 251-259.

18. Taylor T.J. Mutual misunderstanding: scepticism and the theorizing of language and interpretation. Durham, NC, Duke University Press, 1992. 320 p.

19. McKeon R. Communication, truth, and society. Ethics, 1957, no. 67, pp. 89-99.

20. Katriel T., Philipsen, G. «What we need is communication»: «Communication» as a cultural category in some American speech. Communication Monographs, 1981, no. 48. pp. 301-317.

21. Craig R.T., Tracy K. Grounded practical theory: the case of intellectual discussion. Communication Theory, 1995, no. 5, pp. 248-272.

22. Sharkov F.I. Sotsialnye seti kak osnova formirovaniya prostranstva publichnykh kommunikatsiy [Social networks as the basis for the formation of the space of public communications]. Kommunikologiya, 2019, vol. 7, no. 4, pp. 32-40.

23. Andriyanova T.V. Kommunikatsionnaya teoriya R. Kreyga: diskursivnye praktiki i tendentsii vzaimodeystviya $\mathrm{v}$ upravlenii subektom [Craig's communication theory: discursive practices and tendencies of interaction in managing the subject]. Kommunikologiya, 2019, vol. 7, no. 2, pp. 15-24.

24. Andriyanova T.V. Regionalnaya kultura: subektno-obektnye vzaimodeystviya v sfere upravleniya (na primere Kurskoy oblasti) [Regional culture: subject-object interactions in the field of management (on the example of the Kursk region)]. Vektory blagopoluchiya: ekonomika i sotsium, 2019, no. 4 (35), pp. 17-30.

25. Andriyanova T.V., Kirnosova E.N., Starodubtseva I.F. Government order and its significance in the work of the regional cultural establishments. Far East Con. Proc. of the International Scientific Conference (ISCFEC 2018). Part of series: AEBMR. Vol. 47, pp. 175-190. Available at: https://doi.org/10.2991/iscfec18.2019.44 (accessed 28 January 2021).

26. Andriyanova T.V. Demograficheskiy faktor upravlencheskikh resheniy kak osnova sotsiokulturnogo razvitiya regiona [The demographic factor of managerial decisions as the basis for the socio-cultural development of the region]. Sotsialnaya dinamika naseleniya i ustoychivoe razvitiye. II Vserossiyskaya nauchnoprakticheskaya konferentsiya s mezhdunarodnym uchastiyem [Social dynamics of the population and sustainable development. II All-Russian scientific and practical conference with international participation]. Moscow, MAKS Press, 2019. pp. 18-21.

Received: 2 February 2021. 